\title{
Microstructural Evolution of an Experimental Third Generation Single Crystal Superalloy after Long-term Thermal Exposure at $1100{ }^{\circ} \mathrm{C}$
}

\author{
Wang Xiaoguang, Li Jiarong, Liu Shizhong, Shi Zhenxue, Yue Xiaodai \\ Science and Technology on Advanced High Temperature Structural Materials Laboratory, Beijing Institute of Aeronautical Materials, Beijing \\ 100095, China
}

\begin{abstract}
The effects of thermal exposure at $1100{ }^{\circ} \mathrm{C}$ for $100 \sim 800 \mathrm{~h}$ on microstructure of an experimental third generation single crystal superalloy were investigated. The $\gamma^{\prime}$ particles in dendrite core gradually become coarsen and very irregular by $\gamma^{\prime}$ precipitates dissolving resulting from elements diffusion with increasing exposure time. The $\gamma^{\prime}$ precipitates in interdendritic region vary from cuboidal morphology, fusing together, and rafting with the increase of exposure time. The various $\gamma^{\prime}$ particles behaviors between dendritic core and interdendritic region are attributed to the segregation of refractory elements. After $300 \mathrm{~h}$ a small amount of needle-shaped TCP phases are found in dendrite core and the mount of TCP phases increases with increasing exposure time. There is no TCP phase in interdendritic region until $800 \mathrm{~h}$. TEM and EDX measurements show that TCP phases observed in these samples are identified as $\sigma$ phase enriched Re and $\mathrm{W}$ elements.
\end{abstract}

Key words: third generation single crystal superalloy; TCP phase; thermal exposure

The continuous demand of the gas turbine engine manufacturers for an increasing turbine inlet temperature and thrust-weight ratio has pushed the alloy designers to develop nickel-base superalloys with high temperature capability. The superior high temperature mechanical properties of nickelbase single crystal superalloys make them the best candidates for use in key hot section parts of advanced aero engine ${ }^{[1]}$. The demand for enhanced high temperature mechanical strength in these alloys has led to increasingly higher additions of refractory alloying elements to enhance the degree of solid solution strengthening ${ }^{[2,3]}$. The refractory alloying elements, such as Re, W, and Mo can improve the strength and creep performance of single crystal superalloys. However, if the concentrations of the refractory elements are too large, then topologically close packed (TCP) phases may form during exposure to conditions of high temperature and stress ${ }^{[4]}$. TCP phases are characterized as composed of close-packed layers of atoms, and common TCP phases in nickel-based superalloys are known to be $\sigma, \mu, \mathrm{P}$ and $\mathrm{R}$ phases ${ }^{[5]}$. These phases can deteriorate the mechanical properties of superalloys by depleting the matrix of the refractory alloying elements and reduce their solid strengthening effect, delaminating in the fracture zone and acting as initiation sites for fracture at high temperatures ${ }^{[6-13]}$. Microstructure instability of single crystal at elevated temperature during service which causes $\gamma^{\prime}$ coarsening and formation of TCP phases can be a concern for third generation single crystal alloys, so the present study examines microstructural evolution of an experimental third single crystal superalloy after $1100{ }^{\circ} \mathrm{C}$ long-term thermal exposure.

\section{Experiment}

The master alloy of an experimental third single crystal superalloy was melted in a vacuum induction furnace according to the process set by many experiments. The nominal composition (wt\%) of alloy was Cr: 3 6, Co: 8 10, Mo: 0.5 2.5, W: 7 10, Al: 5 7.5, Ta: 6 9, Re: 3 6, Nb: 0.5 2, Hf: $0.01 \sim 0.1$, Ni: balance. The single crystal samples were 
produced in an investment casting cluster mold with $16 \mathrm{~mm}$ in diameter and $200 \mathrm{~mm}$ in length. The single crystal samples were cast in the $<001\rangle$ direction at a constant withdrawal rate of $3.5 \mathrm{~mm} / \mathrm{min}$. The orientation of each bar was determined by $\mathrm{X}$-ray diffraction. Only samples with orientations within $10^{\circ}$ of <001> and without defects were used in this investigation. After casting, the cast rods were subjected to standard heat treatment (solution heat treatment at $1290 \sim 1340{ }^{\circ} \mathrm{C}$ for $10 \mathrm{~h}$, ageing treatment at $1120{ }^{\circ} \mathrm{C}$ for $4 \mathrm{~h}$ and $870{ }^{\circ} \mathrm{C}$ for $32 \mathrm{~h}$ ). Since the blades and vanes of third generation single crystal superalloys worked for long time at elevated temperatures, the long term thermal exposure of the bars after the full heat treatments were performed at $1100{ }^{\circ} \mathrm{C}$ for $100,300,500$ and $800 \mathrm{~h}$. Then, the microstructures of the aged specimens were observed using scanning electron microscopy (SEM) to inspect microstructure stability. The specimens for SEM observation were etched with $4 \mathrm{~g} \mathrm{CuSO}_{4}+20 \mathrm{~mL} \mathrm{HCL}+20 \mathrm{~mL}$ $\mathrm{H}_{2} \mathrm{O}$. Thin foils for transmission electron microscopy (TEM) analysis were obtained by cutting $0.2 \mathrm{~mm}$ thick discs perpendicular to the tensile axis of the specimens using an electric discharge machine. Thin foils were prepared by twin-jet thinning electrolytically in a solution of $10 \mathrm{vol} \%$ perchloric acid and 90vol\% ethanol at $-100{ }^{\circ} \mathrm{C}$ using liquid nitrogen. The JEM-2000FX transmission electron microscope working at $200 \mathrm{kV}$ was used to measure the TCP phase, and the energy dispersive spectroscopy was used for the determination of the chemical composition of TCP phases.

\section{Results}

\subsection{Microstructures after full heat treatment}

As shown in Fig.1, the full heat treatment microstructures of the experimental alloy are found to be composed of $\gamma^{\prime}$ and $\gamma$. It can be seen that the primary $\gamma^{\prime}$ and $\gamma / \gamma^{\prime}$ eutectic dissolve completely after the high temperature solution treatment and that the primary $\gamma^{\prime}$ phase particles show typical cubic morphology with the size of $0.4 \sim 0.6 \mu \mathrm{m}$. The size of $\gamma^{\prime}$ phase particles in dendrite area and interdendritic region becomes uniform.

\subsection{Microstructures after long term thermal exposure}

Microstructures of the full heat treatment samples subjected to long term thermal exposure at $1100{ }^{\circ} \mathrm{C}$ for $100,300,500$, $800 \mathrm{~h}$, are shown in Fig.2, which indicate a growth in the $\gamma^{\prime}$ precipitates with the increasing exposure temperature. It can be seen from Fig.2 that $\gamma^{\prime}$ precipitates in dendritic area gradually become coarsen and very irregular by the reduction of the global internal energy of the system resulting from elements diffusion after exposure of 100, 300, 500 and $800 \mathrm{~h}$. The $\gamma^{\prime}$ precipitates in the interdendritic region do not change its cuboidal morphology after $100 \mathrm{~h}$ exposure with an edge length of about $1 \mu \mathrm{m}$. With the increase of exposure time, some adjacent $\gamma^{\prime}$ particles in interdendritic region meet and fuse together, but they do not produce extended rafts after $300 \mathrm{~h}$. Until thermal exposure of $500 \mathrm{~h}$, most $\gamma^{\prime}$ precipitates change

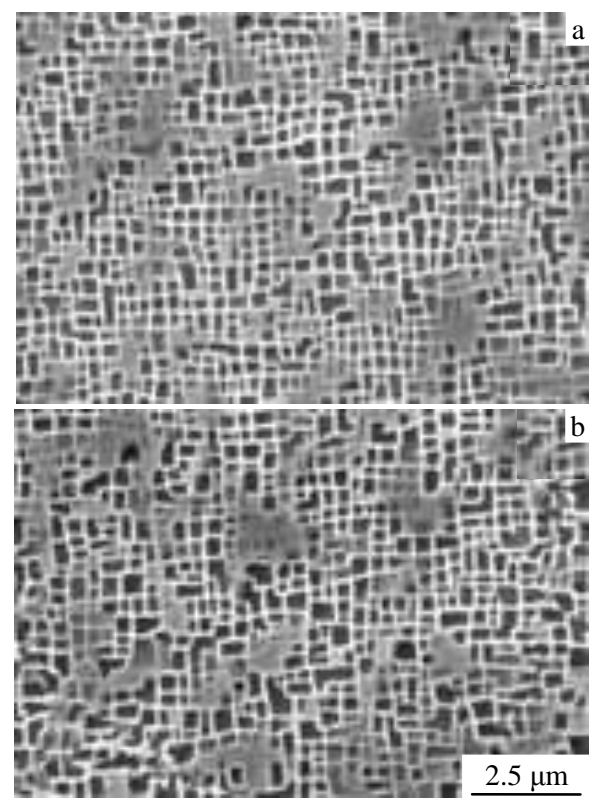

Fig.1 SEM images of the experimental alloys after full heat treatment: (a) dendrite area and (b) interdendritic region

cuboidal morphology for the specimen. After $800 \mathrm{~h} \gamma^{\prime}$ precipitates already link together and form rafts. With growing and linking of the $\gamma^{\prime}$ precipitates, the $\gamma$ matrix channel is widened gradually.

No TCP phases in the dendritic area are observed in the sample exposed after $100 \mathrm{~h}$ while a small amount of needle-shaped TCP are found in the sample exposed after $300 \mathrm{~h}$ at $1100{ }^{\circ} \mathrm{C}$. With increasing aging time, the amount of TCP phases increases gradually. The TCP phases appear as platelets with $\{111\} \gamma$ habit planes. However, there is no TCP phase in the interdendritic region until exposure for $800 \mathrm{~h}$ at $1100{ }^{\circ} \mathrm{C}$ in experimental alloy. This is presumably due to residual chemical heterogeneity originating from the casting process, which has not been completely removed by the solution treatment.

\subsection{Microstructures of TCP under TEM}

TEM images and selected electron diffraction patterns of TCP phases precipitating in the experimental alloy after long term thermal exposure of 500 and $800 \mathrm{~h}$ at $1100{ }^{\circ} \mathrm{C}$ are shown in Fig.3. TCP phases in both samples have a needle-like shape precipitated from $\gamma$ matrix. Chemical composition analysis reveals the higher levels of $\mathrm{Re}$ and $\mathrm{W}$ enriched in this phase as shown in Table 1. The electron diffraction patterns are used to determine the lattice cells for the identification of the TCP phases. Characterization of the TCP phases has indicated that the crystal structure, composition, and orientation relationship of all the TCP phases present in the samples are consistent with those of $\sigma$ phase. Based on these results, the TCP phases observed in these samples are identified as $\sigma$ phase with the same results reported in other alloys ${ }^{[14-16]}$. 


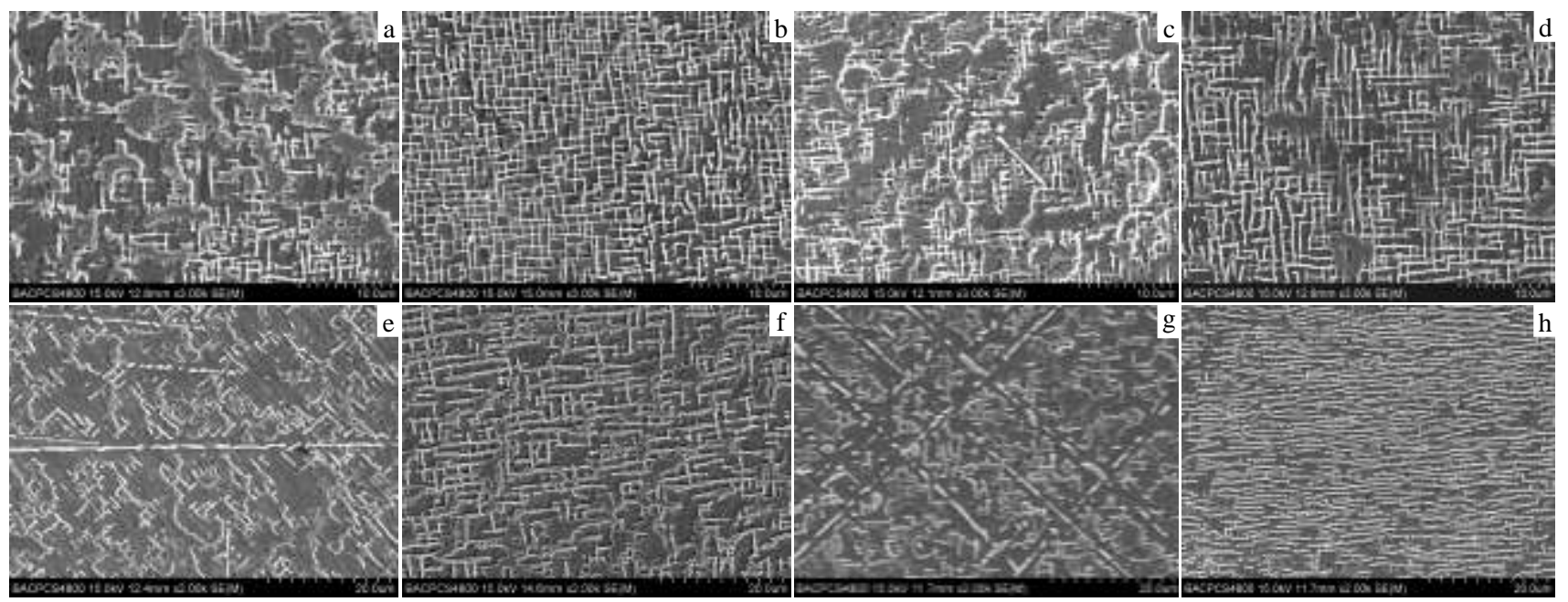

Fig.2 Microstructures of the experimental alloys after long term thermal exposure at $1100{ }^{\circ} \mathrm{C}:(\mathrm{a}, \mathrm{c}, \mathrm{e}, \mathrm{g})$ dendritic area; (b, d, f, h) interdendritic region; (a, b) 100 h; (c, d) 300 h; (e, f) 500 h; (g, h) 800 h

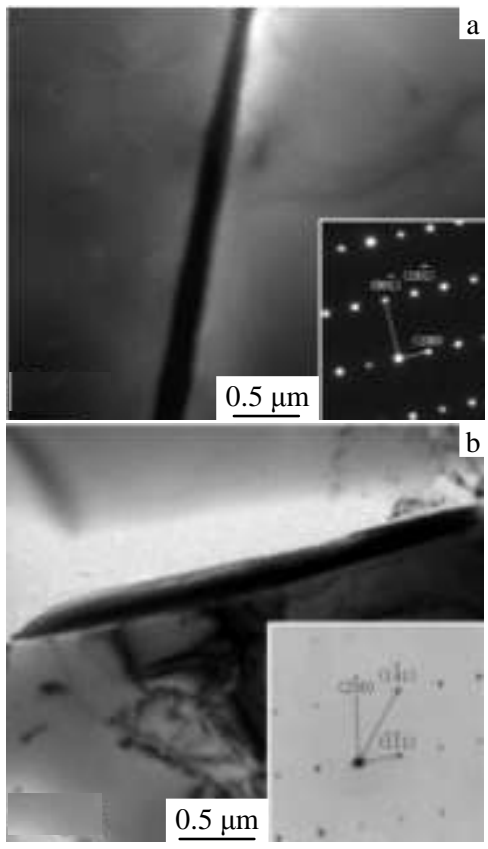

Fig.3 TEM images and selected electron diffraction patterns of TCP phases in this alloy after long thermal exposure at $1100{ }^{\circ} \mathrm{C}$ : (a) $500 \mathrm{~h}$ and (b) $800 \mathrm{~h}$

Table 1 Chemical composition of TCP phase in this alloy given by EDX on TEM

\begin{tabular}{cccccc}
\hline \multirow{2}{*}{ Elements } & \multicolumn{2}{c}{ After exposure of $500 \mathrm{~h}$} & & \multicolumn{2}{c}{ After exposure of $800 \mathrm{~h}$} \\
\cline { 2 - 3 } \cline { 5 - 6 } & $\mathrm{wt} / \%$ & at $\%$ & & wt $/ \%$ & at\% \\
\hline $\mathrm{Cr}$ & 3.6 & 9.2 & & 3.7 & 9.3 \\
$\mathrm{Co}$ & 5.3 & 11.8 & & 5.0 & 11.3 \\
$\mathrm{Ni}$ & 8.9 & 19.9 & & 8.8 & 19.7 \\
$\mathrm{~W}$ & 29.2 & 20.8 & & 29.0 & 20.9 \\
$\mathrm{Re}$ & 51.5 & 36.3 & & 52.1 & 36.9 \\
$\mathrm{Mo}$ & 1.4 & 2.0 & & 1.4 & 1.9 \\
\hline
\end{tabular}

\section{Discussion}

The microstructures in dendritic area and interdendritic region of experimental single crystal superalloy after long term thermal exposure at $1100{ }^{\circ} \mathrm{C}$ is found to be of great difference, for $\gamma^{\prime}$ in dendritic area becomes irregular and coarse, whereas in interdendritic region it still maintains cubic and rafting with increasing thermal exposure time. In order to increase the service temperature of single crystal superalloys, the high amount of refractory alloy elements, such as W, Mo, $\mathrm{Ta}, \mathrm{Re}$, have been used. These increased refractory elements enhance strength and creep resistance ${ }^{[17]}$; at the same time the increased refractory metal content results in much highly segregated microstructure in the as-cast condition, due to the partitioning of these elements to the dendrite core or interdendritic region. The element segregation coefficients $(k)$ of the as-cast alloy, defined as the value of the wt\% composition of the interdendritic region divided by the wt $\%$ composition of the dendritic area for each element, are listed in Table 2. In comparison to the bulk alloy composition, the dendrite cores are significantly enriched in $\mathrm{W}$ and Re while depleted in $\mathrm{Ta}, \mathrm{Al}$, and $\mathrm{Nb}$; conversely, the interdendritic regions of the as-cast microstructure are enriched in $\mathrm{Al}$, Ta and $\mathrm{Nb}$, whereas lower levels of $\mathrm{W}$ and Re are observed. There is still a certain degree of segregation although the alloy is heat treated to homogenize refractory elements, to dissolve the eutectic $\gamma / \gamma^{\prime}$, and to solution the $\gamma^{\prime}$ for subsequent reprecipitation. Therefore, based on these observations, it can be concluded that there still are chemical gradients between dendritic areas and interdendritic regions. On the one hand, the $\gamma^{\prime}$ coarsening process is dominated by Ostwald ripening in the absence of applied stress and is closely dependent on the driving force of $\gamma$ and $\gamma^{\prime}$ forming elements. On the other hand, 
Table 2 Composition of dendritic, interdendritic, eutectic and elements partitioning coefficients of as-cast alloy

\begin{tabular}{ccccccccccc}
\hline Elements & $\mathrm{Ni}$ & $\mathrm{W}$ & $\mathrm{Re}$ & $\mathrm{Al}$ & $\mathrm{Ta}$ & $\mathrm{Nb}$ & $\mathrm{Cr}$ & $\mathrm{Mo}$ & $\mathrm{Co}$ \\
\hline Dendritic core, wt/\% & 60.00 & 9.31 & 6.26 & 4.57 & 5.83 & 0.33 & 3.20 & 1.34 & 9.15 \\
Interdendritic area, wt/\% & 62.99 & 5.83 & 3.02 & 5.64 & 8.73 & 0.87 & 3.22 & 1.28 & 8.43 \\
Eutectic area, wt/\% & 64.91 & 4.06 & 1.38 & 6.40 & 11.31 & 1.22 & 2.33 & 0.69 & 7.69 \\
\hline Partitioning coefficients & 0.95 & 1.60 & 2.08 & 0.81 & 0.67 & 0.38 & 0.99 & 1.05 & 1.09 \\
\hline
\end{tabular}

the $\gamma^{\prime}$ morphology is decided on the cooperation of elastic strain energy and interface energy, so the equilibrium shapes result from the balance between interfacial and elastic energy contributions. Owing to the combination of above reasons, the $\gamma^{\prime}$ phase in dendritic area becomes irregular and worse with long term thermal exposure, whereas in interdendritic region, except for $\gamma^{\prime}$ coarsening, the $\gamma^{\prime}$ particles still remain cubic in the samples after thermal exposure of $100 \mathrm{~h}$ and $300 \mathrm{~h}$, subsequently the $\gamma^{\prime}$ precipitates coarsening and agglomeration occur exposed for $500 \mathrm{~h}$, and eventually the rafting of $\gamma^{\prime}$ precipitates forms after exposure of $800 \mathrm{~h}$.

The three main TCP phases that may precipitate are $\sigma, \mu$ and P. They are generally unwanted, brittle phases that can form during heat treatment or service exposure. In addition to their inherent brittle nature, these phases, which consist primarily of $\mathrm{Cr}, \mathrm{Mo}, \mathrm{Re}$ and $\mathrm{W}$, can also deplete the $\gamma$ matrix of potential solid solution strengthening elements ${ }^{[18]}$. Fig.4 displays the possible time-temperature-transformation curves of three kinds of TCP phases calculated by JMatPro. The input parameters are corresponding to the experimental alloy. Comparing with $\sigma$ phase, it can be seen that the $\mu$ and $\mathrm{P}$ phase obviously form at an early stage during high temperature exposure. Moreover, the $\mu$ and $\mathrm{P}$ phases precipitate after thermal exposure of $20 \sim 30 \mathrm{~h}$ at $1100{ }^{\circ} \mathrm{C}$, while the $\sigma$ phase precipitates after $100 \mathrm{~h}$, which is consistent with experiment results. Some other experiment results show that $\sigma$ is the first phase to form, and other phases form at the expense of the $\sigma^{[19]}$. However, no $\mu$ or $\mathrm{P}$ phase is found in this study. The reason probably is that the $\mu$ or $\mathrm{P}$ phase is the first phase to form, while the precipitation of $\sigma$ phase is the latest in this experimental alloy and they are eventually transformed to $\sigma$ phase. Because of the complexity of TCP, the further

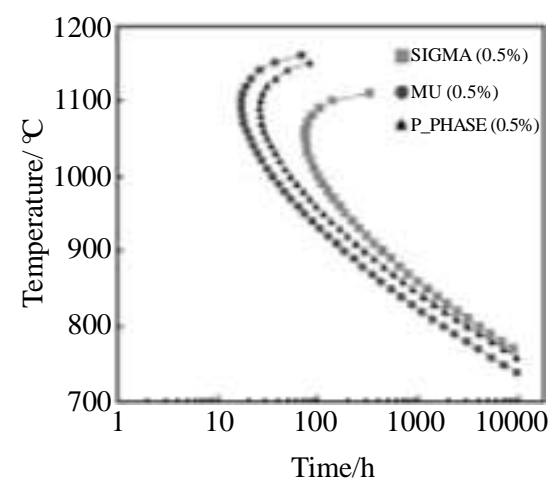

Fig.4 Time-temperature-transformation curves of three kinds of TCP phases in the experimental alloy calculated by JmatPro experiments are still needed.

\section{Conclusions}

1) With thermal exposure at $1100{ }^{\circ} \mathrm{C}$, the $\gamma^{\prime}$ particles in dendrite core gradually become coarsen and very irregular by $\gamma^{\prime}$ precipitates dissolving resulting from elements diffusion with increasing exposure time, while the $\gamma^{\prime}$ precipitates in interdendritic region retain their cuboidal morphology after $500 \mathrm{~h}$ exposure. After $800 \mathrm{~h}$ thermal exposure $\gamma^{\prime}$ precipitates in the interdendritic region link together and form rafts. This difference stems from the segregation of refractory elements.

2) There are no TCP phases precipitating in dendritic core exposure for $100 \mathrm{~h}$, and a small amount of needle-shaped TCP phases occur after $300 \mathrm{~h}$. In the interdendritic region the TCP phases do not precipitate until exposure $800 \mathrm{~h}$.

3) The TCP phases found in the experimental alloy are characterized as $\sigma$ phase and the $\sigma$ phase is mainly composed of $\mathrm{W}$ and Re. The segregation of Re and $\mathrm{W}$, which still exist even after homogenization heat treatment due to the low diffusivity, promotes TCP phase formation in dendritic cores.

\section{References}

1 Atsushi Sato, Hiroshi Harada, Tadaharu Yokokawa et al. Scripta Materialia[J], 2006, 549(9): 1679

2 Erickson G L. Superalloys 1996[C]. Warrendale: TMS, 1996: 35

3 Walston W S, O'Hara K S, Ross E W et al. Superalloys 1996[C] Warrendale: TMS, 1996: 27

4 Pessah M, Caron P, Khan T et al. Superalloys 1992[C]. Warrendale: TMS, 1992: 567

5 Sims C T, Stoloff N S, Hagel W C. Superalloys II[C]. New York: Wiley, 1987: 218

6 Cheng K Y, Jo C Y, Jin T et al. Journal of Alloys and Compounds[J], 2011, 509(25): 7078

7 Yang J X, Zheng Q, Sun X F et al. Scripta Materialia[J], 2006, 55(4): 331

8 Rae C M F. Materials Science and Technology[J], 2009, 25(2): 479

9 Moverare J J, Johansson S, Reed R C. Acta Materialia[J], 2009, 57(7): 2266

10 Tian S G, Wang M G, Li T et al. Materials Science and Engineering $A[\mathrm{~J}], 2010,527(21-22): 5444$

11 Feng Q, Nandy T K, Pollock T M. Materials Science and Engineering A[J], 2004, 373(1-2): 239

12 Simonetti M P, Donnadieu P, Caron P. Scripta Metallurgica et Materialia[J], 1994, 30(12): 1553

13 Darolia R, Lahraman D F, Field R D et al. Superalloys 1988[C]. 
Warrendale: TMS, 1988: 255

14 Yeh A C, Tin S. Metallurgical and Materials Transactions A[J], 2006, 37(9): 2621

15 Acharya M V, Fuchs G E. Materials Science and Engineering $A[\mathrm{~J}], 2004,381(1-2): 143$

16 Shi Z X, Li J R, Liu S Z. International Journal of Minerals,
Metallurgy and Materials[J], 2012, 19(11): 1004

17 Fuchs G E. Materials Science and Engineering $A[\mathrm{~J}], 2001$, 300(1-2): 52

18 Walston W S, Ross W, O'Hara K S et al. US Patent, 5270 123[P]. 1993

19 Rae C M F, Reed R C. Acta Materialia[J], 2001, 49(19): 4113

\title{
一种试验第 3 代单晶高温合金 $1100{ }^{\circ} \mathrm{C}$ 长期时效组织演化
}

王效光，李嘉荣，刘世忠，史振学，岳晓岱

(北京航空材料研究院 先进高温结构材料重点实验室, 北京 100095)

\begin{abstract}
摘 要: 通过 $1100{ }^{\circ} \mathrm{C}$ 长期时效 100 800 h, 研究了一种试验第 3 代单晶高温合金组织演化规律。结果表明：随着时效时间的增加, 枝 晶干 $\gamma^{\prime}$ 相逐渐变得粗大和不规则; 而枝晶间 $\gamma^{\prime}$ 相形貌则随着时效时间的延长呈规则立方、合并长大、筏排化规律演化。枝晶干与枝晶间 这种不同的 $\gamma^{\prime}$ 相演化规律主要由合金元素的偏析造成。时效 $300 \mathrm{~h}$ 后，枝晶干析出了少量的针状 TCP 相，随着时效时间增加，枝晶干处 $\mathrm{TCP}$ 相析出量增加; 枝晶间直到 $800 \mathrm{~h}$ 仍未发现 TCP 相析出; TEM 和 EDX 分析表明析出相为 $\sigma$ 相, 富含 Re、W 元素。
\end{abstract}

关键词：第 3 代单晶高温合金; TCP 相; 长期时效

作者简介: 王效光, 男, 1978 年生, 硕士, 北京航空材料研究院先进高温结构材料重点实验室, 北京 100095, 电话: 010-62498312, E-mail:wxg973@126.com 